\title{
Simulator of ThERMOMECHANiCAL TREATMENT OF METAlS
}

\author{
Josef Káňa, Ivan Vorel, Andrea Ronešová \\ University of West Bohemia in Pilsen, Czech Republic
}

\begin{abstract}
The development and optimisation of heat treatment and mechanical working of forged parts would be very timeconsuming and costly if carried out right in the production line. For this reason, a thermomechanical simulator has been developed. Using the simulator, mechanical loads, as well as loads from forces, deformation and heat acting on a real-life product during various manufacturing processes can be simulated. The present paper describes this testing system and the related methodology. The agreement between the characteristics of a real-life product and the data from the simulator is demonstrated using an example of a closed-die forging. The comparison involved mechanical properties and microstructures. Results achieved on numerous other products, such as sheet metal, rods, wires and others, prove that material-technological modelling with the aid of this newly-developed equipment is a cost-effective method of modelling real-life manufacturing processes in laboratory conditions.
\end{abstract}

Keywords: heat treatment and mechanical working; simulation; LabView; forging; heating; cooling
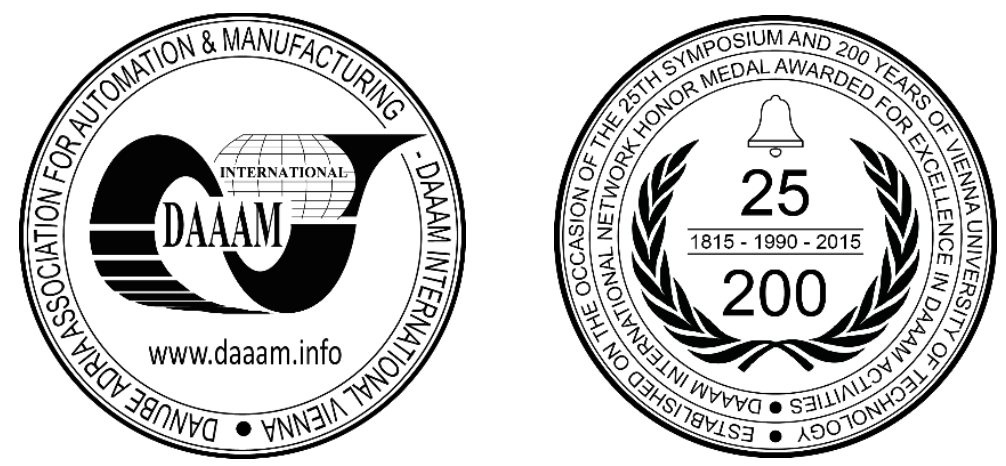

This Publication has to be referred as: Kana, J[osef]; Vorel, I[van] \& Ronesova, A[ndrea] (2016). Simulator of Thermomechanical Treatment of Metals, Proceedings of the 26th DAAAM International Symposium, pp.0513-0518, B. Katalinic (Ed.), Published by DAAAM International, ISBN 978-3-902734-07-5, ISSN 1726-9679, Vienna, Austria DOI: 10.2507/26th.daaam.proceedings.069 


\section{Introduction}

Today, great emphasis is laid on production quality but at the same time there is a pressure on the lowest possible production cost. Arising from this combination is the demand for continuous and rapid technological development of manufacturing processes. As far as the production of formed parts is concerned, this translates into optimisation of heat treatment or thermomechanical processing in order to reduce their energy consumption and time demands. At the same time, this tool can be used for substituting the current materials with less costly alternatives based on cost-effective chemistries, while improving the resulting mechanical properties and performance characteristics of the products.

If such research and optimisation were to be conducted in the production line, they would become very time consuming and costly. For these purposes, a simulator of thermomechanical treatment has been developed. Using this simulator, forming as well as heat treatment can be simulated.

The newly-developed methodology enables engineers to achieve very good agreement between laboratory simulations and results from a real-world production process. This agreement between results has been verified successfully with numerous and diverse products in terms of both microstructures and mechanical properties. In the present article, attention is devoted to the use of this method for developing a manufacturing route for a closed-die forging.

\section{Thermomechanical Simulator}

The simulator of thermomechanical processes is under long-term development at the departments of the Research Centre of Forming Technology based at University of West Bohemia in Pilsen. Its primary purpose is laboratory-based simulation and optimisation of real-world processes used in thermomechanical treatment of metals in industry. With this system, forming processes $[6,7,8]$ can be simulated while maintaining the required temperatures in the specimen. Thanks to long-standing experience and continuous development efforts, the equipment offers a good agreement between the outcomes of laboratory simulations and the characteristics of real-world forged parts made in actual production lines [1, $3,4]$.

The simulator consists of three subsystems. Its core is the MTS FlexTestSE electro-hydraulic testing system which offers the maximum load of $50 \mathrm{kN}$ at actuator speeds of up to $3 \mathrm{~m} / \mathrm{s}$. Applying mechanical forces to the test piece, it is also the central control unit of the entire machine. It maintains two-way communication with the other two subsystems which control the specimen temperature.

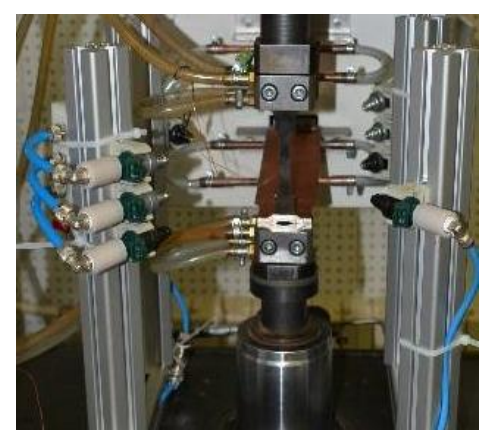

Fig. 1. Thermomechanical simulator with a sheet specimen mounted

The second subsystem is a specimen heating system. It relies on high-frequency electrical resistance heating. At its core, there is a multi-stage controller as a single-chip computer and FPGA with a patented power converter control method [2]. The power source parameters are $230 \mathrm{~V} / 16 \mathrm{~A}$; the maximum current passing through the specimen is $1 \mathrm{kA}$. The controlled quantities include the current and the frequency. The frequency of the control loop is $16 \mathrm{kHz}$. Feedback is provided by a thermocouple attached to the test specimen. With the maximum power of the system of $3 \mathrm{~kW}$, specimens can be heated in a controlled manner at rates in excess of $200{ }^{\circ} \mathrm{C} / \mathrm{s}$, depending on the material and shape of the test piece. The accuracy of the specimen temperature is limited by the accuracy of the thermocouples. The variation is no more than $\pm 2{ }^{\circ} \mathrm{C}$ from the value indicated by the thermocouple.

The third subsystem of the simulator is the cooling system. Like the others, it is a feedback-based unit linked to the heating system. The heating system transmits digital data on the current specimen temperature and the set point temperature. If the specimen temperature is lower than the set point temperature, heating is activated. In the opposite case, the cooling system is activated automatically. The coolant is an air-water mixture of variable ratios applied at varying intensities. The control is based on an in-house non-linear algorithm. The program for the cooling system has been developed using LabView environment and runs on myRio (see: http://www.ni.com/myrio/). Due to its nature, the cooling system has a slower response than the heating system because it contains mechanical parts. Despite that, the actual specimen temperature was successfully kept very close to the required value, even at the high rates of change in the temperature. The maximum available controlled cooling rates are up to $100{ }^{\circ} \mathrm{C} / \mathrm{s}$. 
The controllers of the cooling and the heating systems communicate and maintain the prescribed specimen temperature profile throughout the process without any need for the operator's intervention.

\section{Methodology of thermomechanical modelling}

The first step in thermomechanical modelling is acquiring the necessary data on the production line, particularly the temperature and deformation profiles regarding the forged part in question [5]. This data together with other parameters is used for developing a numerical model of the forged part. With the aid of the results from the model, the process conditions and parameters in selected locations of the forged part are determined which are critical to the part and cannot be obtained by measurement on the production line. This data is employed in the material-technological modelling sequence in the thermomechanical simulator.

A procedure that defines the deformation process, the temperature profiles, logging rates and other parameters must be developed using the control system of the simulator for each test to be conducted. The control system then provides mechanical loading of the specimen, continuous data visualization and logging functions. It sends the set point temperature data via the analogue output line to the heating control unit. The heating control unit is responsible for heating the specimen to the desired temperature. For the purpose of visualisation and logging, the current actual specimen temperature value is sent to the control unit as an analogue signal as well. The set point temperature is maintained through the heating and cooling systems working together. Each system uses only the current temperature values: the set point value and the actual value.

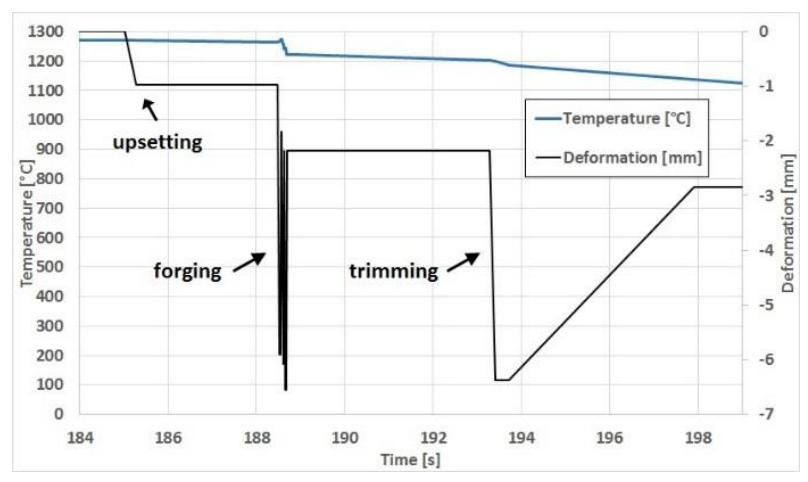

Fig. 2. Example of a procedure where deformation simulates individual forming steps used in making a particular forging. Only the region with deformation is shown. Outside this region, no deformation is prescribed and no force is applied to the specimen. Thus, the specimen thermal dilatation is not restricted

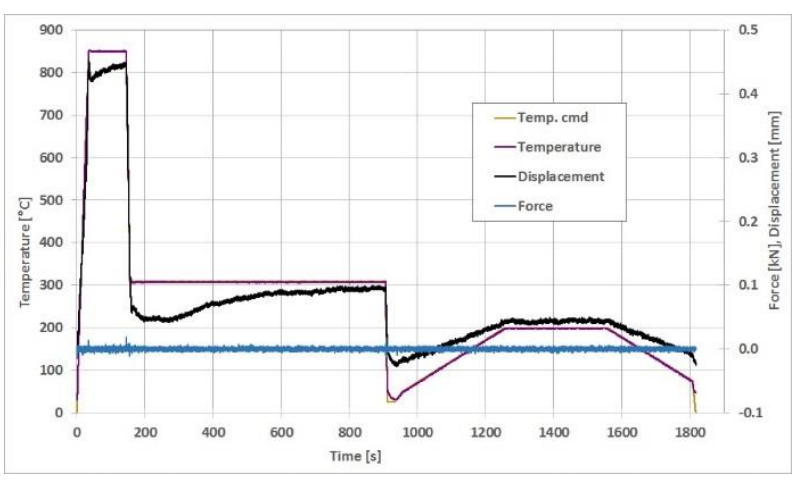

Fig. 3. Example of physical simulation involving heating to austenite region, rapid cooling to $350{ }^{\circ} \mathrm{C}$ and subsequent holding at a constant temperature. The process comprises no forming steps. Zero force is applied and the specimen dilatation is not restricted

An example of a process for which multiple-step deformation is prescribed is the part of a forming sequence for making a closed-die forging shown in Fig. 2. Another example of a process involving rapid changes in temperature is press hardening where cooling stops at a prescribed temperature (Fig. 3). The deformation curve shows a transformation region during heating and another - martensitic transformation - approximately 150 seconds into the process. The force curve demonstrates that zero force was applied throughout the entire test and thus the specimen dilatation was not restricted.

The advantage of the simulator is in that zero force can be applied during one part of the test and the specimen thermal dilatation can therefore be unrestricted, whereas deformation can be applied during other parts of the test. This is typically used in testing of forming processes: the zero-force mode is used during heating, after which the deformation mode is applied and the specimen is deformed as specified and, subsequently, the machine returns to the zero-force mode. In this manner, an entire manufacturing route can be simulated and the prescribed forming and temperature parameters can be maintained.

\section{Experimental}

\subsection{Forged part}

The demonstration product chosen for verifying the closed-die forging simulation methodology was a forged part from C45 steel used in automotive industry (Fig. 4). The process simulation was carried out for P10 and P26 points, which are locations with the largest and the smallest plastic strain (Fig. 5). 


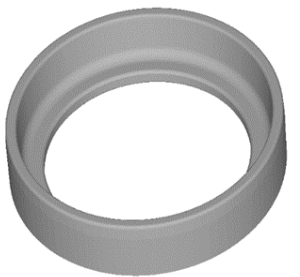

Fig. 4. Demonstration forged part which was chosen for the experiment

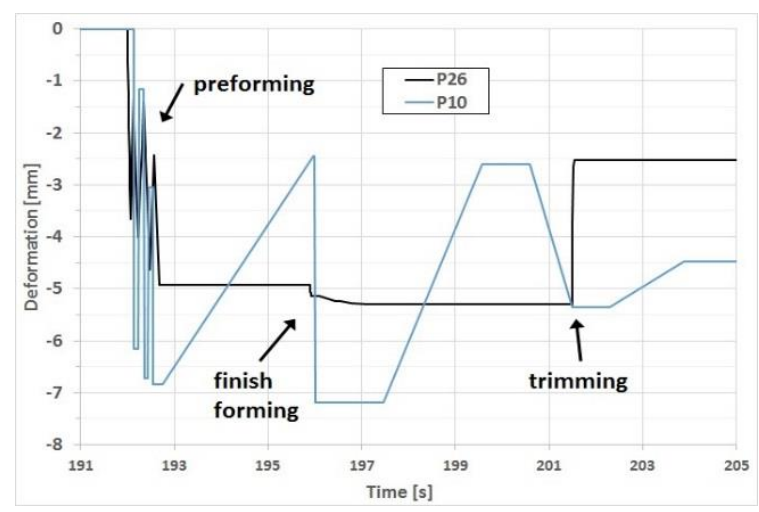

Fig. 6. Comparison of deformation profiles during forging process at points P10 and P26 in the forging (see Fig 5.)

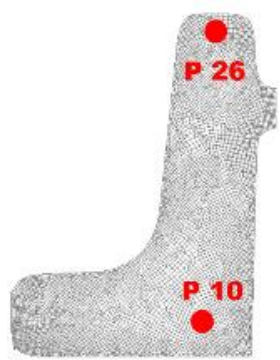

Fig. 5. Cross-section through the forged part. Locations selected for the process simulation on the basis of FEM calculations are identified

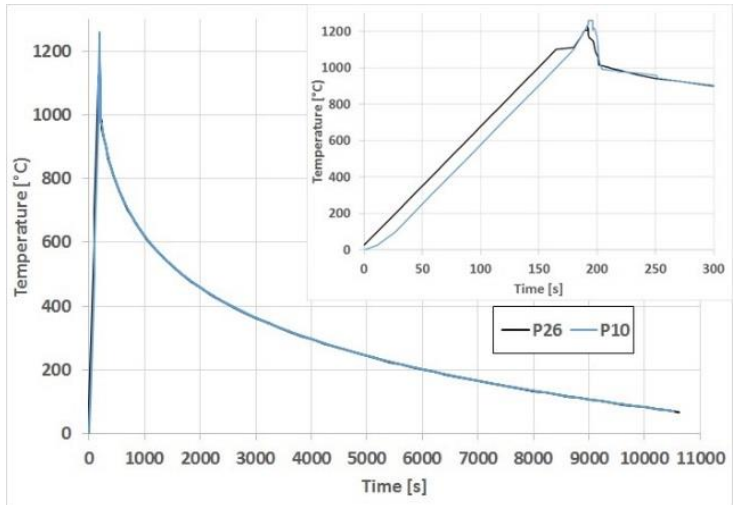

Fig. 7. Temperature profiles for both points (the initial heating stage is shown enlarged in the inset)

The deformation profiles (Fig. 6) were adopted from the results of FEM simulations. Outside this short deformation period, zero force is applied in the test and the specimen dilatation is not restricted. Significant differences between temperatures at points P10 and P26 only occur during heating (Fig. 7). At the controlled-cooling stage, the difference is minimal and the curves overlap. The inset shows the enlarged plot of the initial heating region. The temperature at point P10 clearly increases more slowly than at the other point. The reason is that the location is further from the part's surface and within a more massive portion of the part.

\subsection{Comparison of results for the real-world forged part and the physical simulation specimen}

The microstructures of the actual forging and the simulation specimen are shown in Figs. 8 through 11. The microstructure of the actual forging is on the left while that of the simulation specimen is on the right. It is clear that the ferritic-pearlitic microstructures are identical.

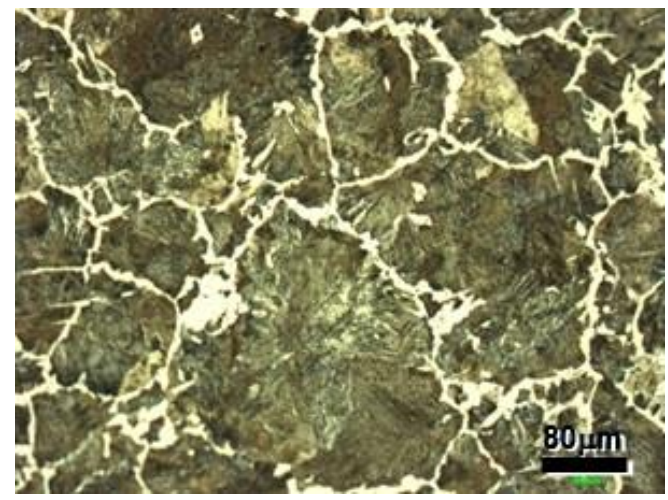

Fig. 8. Microstructure of the real-world forging at point P10 with a hardness of $221 \mathrm{HV} 10$

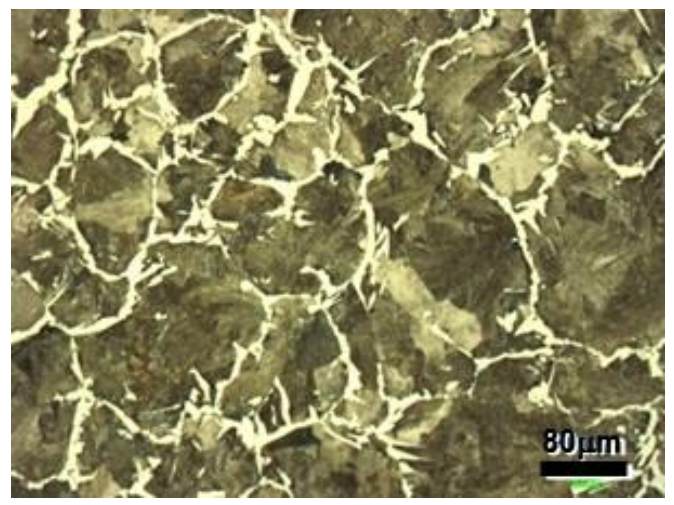

Fig. 9. Microstructure of the specimen processed in the simulator using the parameters for the point P10; hardness: $226 \mathrm{HV} 10$ 


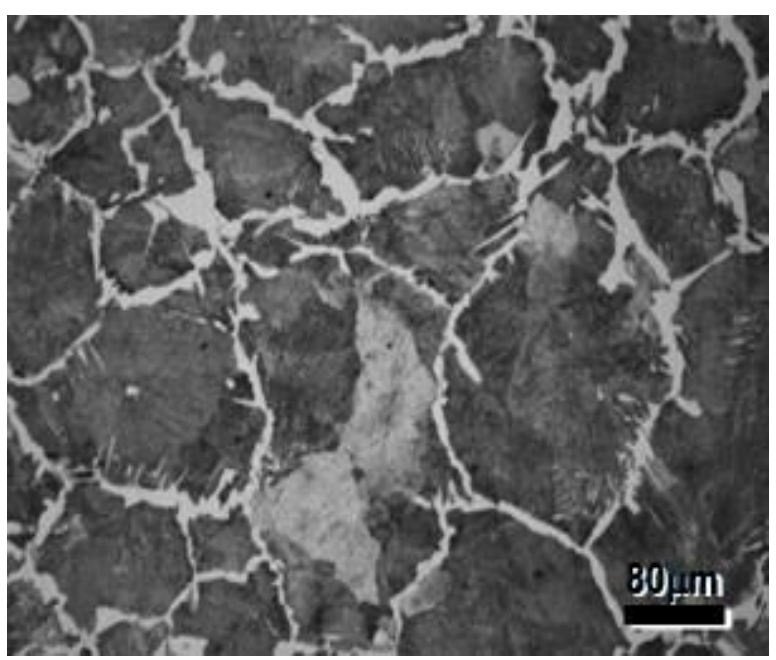

Fig. 10. Microstructure of the real-world forging at point P26 with a hardness: 204 HV10

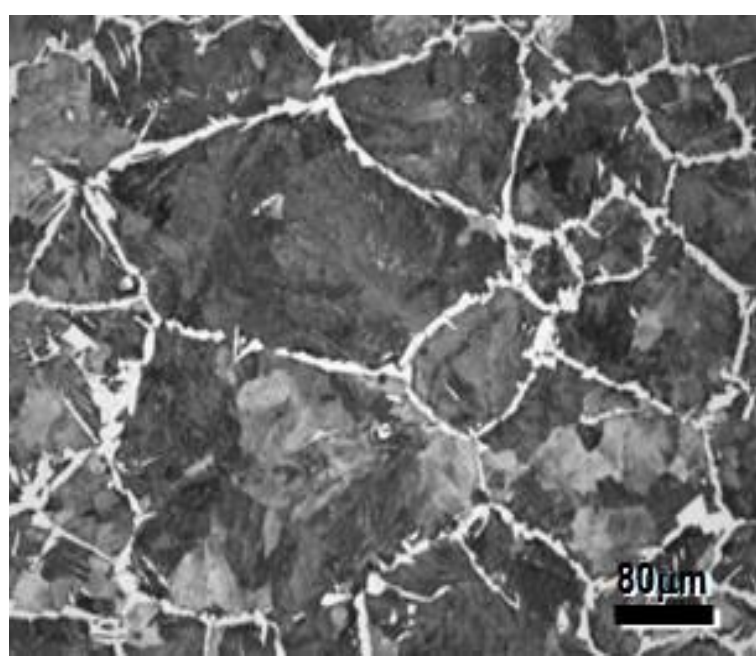

Fig. 11. Microstructure of the specimen processed in the simulator using the parameters for the point P26; hardness: 213 HV10

\begin{tabular}{|l|l|l|}
\hline $\begin{array}{l}\text { Location in the } \\
\text { forged part }\end{array}$ & Actual forged part & $\begin{array}{l}\text { Specimen processed in the } \\
\text { simulator }\end{array}$ \\
\hline P10 & 221 HV10 & 226 HV10 \\
\hline P26 & 204 HV10 & 213 HV10 \\
\hline
\end{tabular}

Table 1. Comparison between hardnesses of the forged part and the specimen processed in the simulator

\section{Conclusion}

The thermomechanical simulator and the related methodology enable physical simulation of material processing in laboratory conditions to be carried to match the way the processing takes place in the real-world forming, heat treatment and thermomechanical treatment sequences. The present case involved a manufacturing route for a forged part. An analysis of the process and step-by-step optimisation of its parameters have been carried out. The fact that there are only minimal discrepancies between the results of physical simulation in a simulator and the results of a real-world forging process was demonstrated using a particular medium-sized forged part from C45 material. Attention has been devoted to achieving comparable microstructures and hardness attributes, i.e. mechanical properties and the local conditions of the pearlitic-ferritic microstructure at the locations of interest within the forged part.

The physical simulation carried out in a simulator under laboratory conditions demonstrated that this method is usable in the specific conditions of closed-die forging. This investigation expanded the portfolio of complex metallurgical processes whose modelling has been mastered. It was shown that this tool offered a cost-effective method of optimising existing processing sequences and developing new products and new materials.

The main benefit of the thermomechanical simulator developed and the related methodology is the opportunity to study in great detail the thermomechanical processing and forming of metallic materials and products in a laboratory environment and under conditions identical to the real-world manufacturing process. Thanks to this capability, the potential use of novel materials can be explored and heat treatment processes optimised for various purposes, be it the reduction of manufacturing costs, enhancement of the parameters of final products or other goals.

The simulator is planned to be developed further and the methods are to be expanded for finding information about the particular sequence in question, including those processes that take place in the material during its microstructural evolution.

\section{Acknowledgements}

This paper contains results created obtained under the projects SGS-2013-028 Support of Students' Scientific Activities in the Area of Material Engineering and SGS-2014-022 New Martensitic Structures - Process Parameters and Properties. These projects are subsidised from specific resources of the state budget for research and development. 


\section{References}

[1] B. Mašek, H. Jirková., L. Kučerová, A. Ronešová, J. Malina, Material-Technological Modelling of Real Thin Sheet Rolling Process. METAL 2011. 20th Anniversary International Conference on Metallurgy and Materials, 2011, pp. 216-220. Ed. TANGER, ASM Int, Mat Informat Soc; CSNMT; VSB-TU. ISBN 978-80-87294-24-6.

[2] A.Ronešová, B.Mašek, Digital generator of phase shift modulation, US Patent 7480 155, 2009, Available from: http://www.google.com.ar/patents/US7480155.

[3] I. Vorel, V. Pileček, F. Vančura., H. Jirková, B. Mašek, Material-Technological Modelling of C45 Steel Die Forgings. Procedia Engineering. 2015, Vol. 100, Issue C, pp. 714-721, ISSN 1876-6102.

[4] F. Vančura, I. Vorel, V. Pileček, B. Mašek, Material Technological Modeling of Thermomechanical Processing of Die Forging of Microalloyed Steel, Kovárenství. 2015, ISSN 1213-9289.

[5] N. Yukawa, Y. Nakashima, T. Ishiguro, E. Abe, T. Ishikawa, T. Choda, Modeling of Heat Transfer Coefficient of Oxide Scale in Hot Forging. Procedia Engineering, Volume 81, 2014, Pages 492-497, ISSN 1877-7058.

[6] P. Liu, R. Liu, Y. Wei, H. Yang, Q. Yong, Y. Bao, Austenite dynamic recrystallization of the microalloyed forging steels 38MnVS during forging process. Procedia Engineering, Volume 27, 2012, Pages 63-71, ISSN 1877-7058.

[7] V. Lazić, D. Arsić, R. Nikolić, S. Aleksandrović, M. Djordjević, B. Hadzima, J. Bujnak, Experimental Determination of Deformations of the Hard Faced Samples Made of Steel for Operating at Elevated Temperatures. Procedia Engineering, Volume 111, 2015, Pages 495-501, ISSN 1877-7058.

[8] L. Chen, J. Huang, Y. Zhao, H. Di, F. Zhu, Processing, Microstructures and Mechanical Properties of Ultra-high Strength Steel Sheet. Procedia Engineering, Volume 81, 2014, Pages 84-89, ISSN 1877-7058. 